\title{
Effectiveness index for environmental impact assessment methodologies
}

\author{
A. L. Caro \& J. J. Toro \\ Universidad Nacional de Colombia, Colombia
}

\begin{abstract}
The Environmental Impact Statement (EIS) is a basic tool for decision-making about activities that may affect the environment. Because of its importance, the EIS should include impact assessment methodologies with thorough structures and implementation, so that the results obtained regarding possible environmental impacts are accurate. Due to the need for quality and performance parameters, an index of effectiveness is proposed to evaluate the methodologies used for that purpose. This was designed in three phases: i) identification of analysis parameters; ii) indicators setting; and iii) formulation of the mathematical expression. The effectiveness index for environmental assessment methodologies (EIM), incorporates two weighted elements: i) the structural parameters value (SPV) that refers to the concept of efficacy related to the design of the methodology and its components. It has four weighted variables: a) totality; b) objectivity; c) relevance; d) accuracy and an uncertainty factor (UF) established from opinions by experts. ii) The operating parameters' value (OPV), represents the efficiency of the evaluation and it articulates the development of the methodology, the stakeholders and resources employed. The OVP includes three weighted variables: a) interdisciplinarity; b) expertise; and c) participation. To assign the value of variables, a system of descriptive indicators is proposed. From the implementation of the EIM it is concluded that the methodologies used to evaluate environmental impacts in Colombia during the period 2012-2014 are not effective, for this reason the actions taken around these and possible management are insufficient because are not addressed the impacts that were poorly evaluated. The use of this tool is recommended to identify failures in the methodology in order to generate control strategies.
\end{abstract}

Keywords: assessment, effectiveness, environmental impact, index. 


\section{Introduction}

Effectiveness can be catalogued as the capacity for achieving the intended, wanted or expected result, it refers to the functioning of something as intended and achieving the purpose for which it was designed. In order to make the Environmental Impact Assessment (EIA) effective, it is required the use of appropriate methods to evaluate the impacts regarding the project intended to be executed [1].

The concept of effectiveness is used in different areas of knowledge having an important role in evaluation of techniques and methodologies. An evidence of this is the composition of technical guidelines which process the correct execution of processes through indicators and other tracking tools. Inside the environmental field, this term has been merged with the intention of verifying that the EIA generates reliable results which enables the making of assertive decisions related to the impact of construction works and other activities within ecosystems [1-4]. Thus resolving one of the main issues manifested when developing an EIA: the possibility of result manipulation as a consequence of the flexibility implied in the chosen resources and the subjective view of the evaluator. In Colombia, although normativity determines as mandatory presenting an EIS in order to process an environmental license for construction works and/or functioning of projects, works and activities (PWA), there are no methodologies nor official procedures to develop these kind of studies, a reason for which evaluators may distort results and turning the EIS not as effective as expected due to the lack of reliable information to make decisions about the handling of probable incoming impacts .

In a process such as EIA, where decisions are taken based on predictions, it is mandatory to take into consideration the existence of uncertainties, because the real impacts may differ from those previously identified due to the dynamic condition of the interaction between the PWA and the environment. Furthermore, the evaluation is carried out by the proposers and evaluators interested in the approval of the Environmental License and although it is a process developed under supported predictive models, not in all cases, scientifically, uncertainty is present, creating an effect different than expected, especially the assessment of impacts may be less than the real.

Uncertainty is present at every stage of EIS, mainly in identification and prediction of impacts, depicting a knowledge/ignorance statement about the discussed issue. When cause-effect relations inside a system known and recognized, even in a vague manner, impacts can be predicted or at least described; however, some remain unknown until they occur [5]. Tennøy et al. [6] compare the uncertainty present in predictions of impact in a project without location against the impacts observed in a project with location and find that $58 \%$ of the impacts are imprecise or inexact. In this regard there is scientific evidence which recognizes the inevitable uncertainty inherent to the predictions of the EIS. Auditing studies have shown that real environmental impacts from the PWA, these often differ from the foreseen or evaluated impacts [7-9]. Uncertainty in predictions is one of the main considered issues when studying EIS. In view of the foregoing, if data uncertainty is not considered in the final reports, the predictions 
presented as a product of the environmental assessment appear to be more precise than what they actually are.

Although it is impossible to completely eliminate uncertainty from identification and assessment of impacts, it is viable to create quantitative tools which allow its reduction and incorporation, through mathematical models which include cause- effect relations [6]. To that end it is necessary to include variables and indicators that can be measured in an objective way ensuring the effectiveness of the process. Effectiveness in EIS is constantly evaluated, but this issue it's not analyzed in the environmental impact evaluation methodologies used in EIS. Consequently, a need arises for the implementation of tools which facilitate the tracking for these sorts of methodologies. Because, in order to verify if the impact assessment is correct, one must wait for the finishing of the work of activity, once the ecosystem has been transformed and the related impacts are evident, providing cases where conditions may be irreversible for the environment.

\section{Effectiveness in methodologies used for EIS}

In order to establish parameters to determine an effectiveness index for environmental assessment, an index was designed which incorporates parameters belonging to the structure and implementation of it.

\subsection{Establishment of analysis parameters}

According to recommendations made by Senécal et al. [10] aimed toward the correct development of the EIS, seven parameters are proposed to estimate effectiveness in methodologies used in Environmental Impact Statements. These parameters are arranged in two categories: i) structural parameters' value, regarding the design of the methodology and the element which constitute them and ii) operative parameters' value, regarding the way of execution of the methodology, the parties involved and resources used. Up to establishing analysis parameters, effectiveness is considered as the conjunction of efficiency and efficacy criteria [4], setting a correspondence between structural parameter value and procedure effectiveness, in relation with operative parameter value likened with transactive effectiveness. The assessment of these parameters determines the compliance of the objectives from the methodology and the restoration of its initial application purpose involving substantial/substantive (Table 1).

It is inferred that procedure effectiveness relates to "efficacy" having as an analysis locus the quality of the procedures, methods and techniques used to achieve the previously established objective. Transactive effectiveness is interpreted as "efficiency", which assesses the compliance of the objective according to resources use. Substantial/substantive effectiveness focuses on achieving the foreseen objectives. If we merge the optimization of labour designated resources, it may be evaluated at issue of efficacy and efficiency. 
Table 1: Parameters for effectiveness estimation in assessment impact methodologies.

\begin{tabular}{|c|c|c|c|c|}
\hline \multicolumn{2}{|c|}{$\begin{array}{c}\text { Type of } \\
\text { effectiveness }\end{array}$} & $\begin{array}{c}\text { Type of } \\
\text { parameter }\end{array}$ & $\begin{array}{l}\text { Analysis } \\
\text { parameters }\end{array}$ & Parameters' description \\
\hline \multirow{7}{*}{ 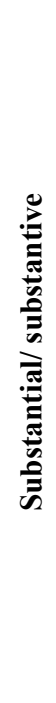 } & \multirow{4}{*}{ 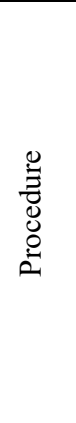 } & \multirow{4}{*}{ 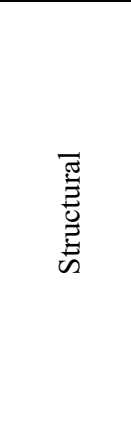 } & Wholeness & $\begin{array}{l}\text { Consideration of all the components and } \\
\text { environmental factors that could be } \\
\text { affected }\end{array}$ \\
\hline & & & Objectivity & $\begin{array}{l}\text { Use of qualitative and quantitative } \\
\text { methods }\end{array}$ \\
\hline & & & Relevance & $\begin{array}{l}\text { Use of relevant attributes for impacts } \\
\text { evaluation }\end{array}$ \\
\hline & & & Accuracy & $\begin{array}{l}\text { Use of standard, replicable and suitable } \\
\text { techniques which fit the purpose of the } \\
\text { study. }\end{array}$ \\
\hline & \multirow{3}{*}{ 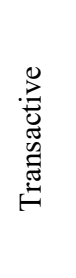 } & \multirow{3}{*}{ 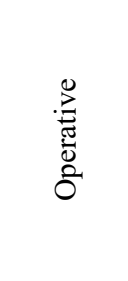 } & Interdisciplinarity & $\begin{array}{l}\text { Inclusion of specialists in different } \\
\text { disciplines }\end{array}$ \\
\hline & & & Expertise & $\begin{array}{l}\text { Coherence between the between the scope } \\
\text { of the evaluators and the work to be } \\
\text { performed. }\end{array}$ \\
\hline & & & Participation & $\begin{array}{l}\text { Inclusion of the community in the final } \\
\text { decision about the impact significance. }\end{array}$ \\
\hline
\end{tabular}

\subsection{Formulation of indicators}

In the EIS indicators generally are used as a base line to describe the environment, for, as mentioned by Munn [11], there are parameters which will enable us to analyze the magnitude of environmental impact. For the purpose of this investigation, it is raised a system of indicators in order to assign a value to the analysis variables compounding the effectiveness index. The eligible indicators are descriptive, they provide an understanding of past and current conditions [12]. Both for structural variables as for operative variables, state indicators are presented.

\subsection{Formulation of the mathematic expression}

The mathematic expression integrates two pondered characters, compiled by pondered variables whose value is estimated from the previously formulated indicators. In order to ponder the index components, it was conducted a consultation to selected experts according to their experience and works related with the EIS. Said consultation was performed following the proposed guidelines in the Delphi Method [13]. The consulted group was constituted by 16 selected professionals in a local level, with experience time in the investigation and development of EIS between three and six years. It was deployed with a structured survey, with open and closed questions, with dichotomous answers, pondered with the Likert method. 


\subsubsection{The effectiveness index (EIM)}

The effectiveness index for environmental assessment methodologies (EIM) is an expression which allow to integrate the operative and structural component of the methodology in order to determine if it fulfills with the objectives proposed using destined resources in an optimal manner. When considering the relation between efficiency and efficacy it generates as a result an effectiveness percentage, as depicted in Eq. (1)

where:

$$
\mathrm{EIM}=[(\alpha \mathrm{SPV}-\mathrm{UF})+\beta \mathrm{OPV}]^{*} 100
$$

$\mathrm{EIM}=$ effectiveness index for environmental assessment methodologies; SPV = structural parameters value; $\mathrm{UF}=$ uncertainty factor; $\mathrm{OPV}=$ operating parameters value; $\alpha=0.7 ; \beta=0.3$

Eq. (1) is constituted by the structural parameters value (SPV) from which it is subtracted the Random uncertainty factor (UF) plus the operating parameters (OPV). The result of the index is formulated as a percentage which depicts the rate of effectiveness of the methodology. From the experts' consultation it was determined that the SPV corresponds to $70 \%$ above the final value, therefore the weighting factor, $(\alpha)$ corresponds to $=0.7$ and the OPV represents the $30 \%$ remaining $\beta=0.3$. This is largely due to the difficulty in the modification of the evaluation methodology once its use has begun, on account of a change structure it turns out to be extremely complex and, giving the case of conducting it, it can be interpreted as a strategy to manipulate the results of the evaluation. In addition, once an operative malfunction is detected with in the implementation of the methodology, it ca be easily a starting point for change.

Figure 1 depicts the possible results from the EIM taking into account values from ( $\alpha$ SVP - UF) and $\beta \mathrm{OPV}$ that range from 0 to 0.65 and from 0 to 0.30 respectively. As shown, the result of the EIM variated between 0 and $95 \%$,

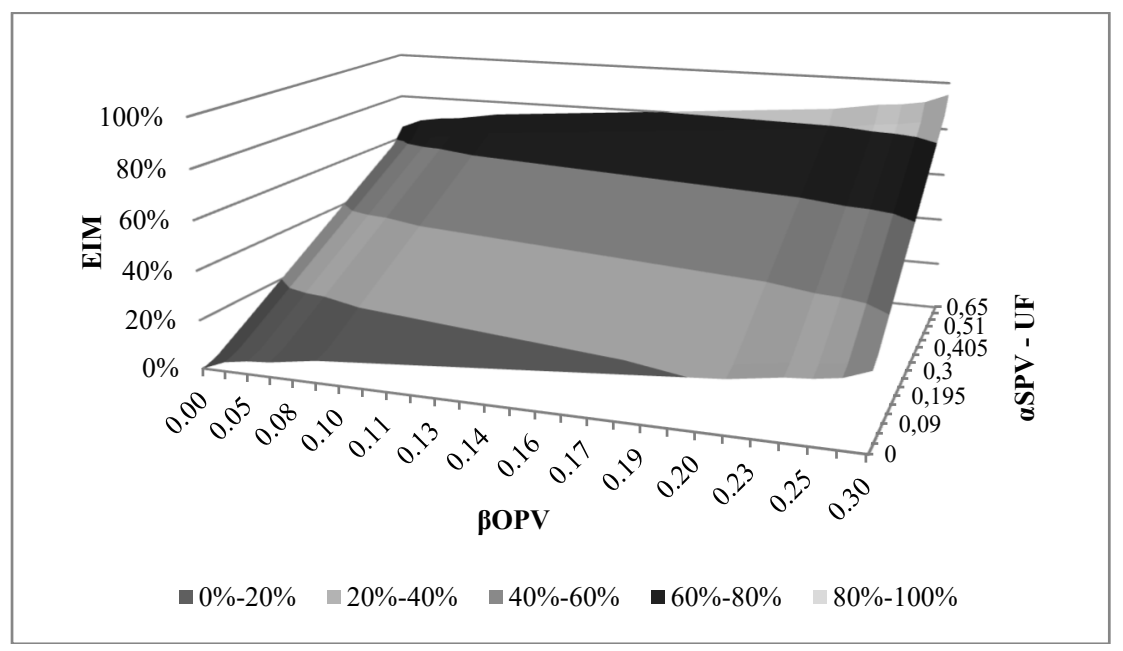

Figure 1: Relation between EIM, $(\alpha \mathrm{SPV}-\mathrm{UF})$ and $\beta \mathrm{OPV}$ values. 
therefore a methodology has a minimum $0 \%$ of effectiveness and a maximum of $95 \%$. This is linked to the impossibility of having a totally effective methodology due to the inherent uncertainties of interactions among the OPV and the environment, as will be explained later.

Effectiveness is categorized according to the values compiled in Table 2. Similarly, we present the characteristic of the methodologies located in each of the established categories.

Table 2: $\quad$ Values scale for the IEM results.

\begin{tabular}{|c|c|c|}
\hline $\begin{array}{c}\text { Level of } \\
\text { effectiveness }\end{array}$ & Range & Description \\
\hline High & $\begin{array}{c}81 \%- \\
95 \%\end{array}$ & $\begin{array}{c}\text { The methodology is effective, the evaluation results are reliable } \\
\text { and the impact present high probability to behave according to the } \\
\text { final result of EIS. }\end{array}$ \\
\hline $\begin{array}{c}\text { Medium- } \\
\text { high }\end{array}$ & $\begin{array}{c}61 \%- \\
80 \%\end{array}$ & $\begin{array}{c}\text { The methodology presents a solid structure but it still needs to } \\
\text { improve some aspects to present reliable results. }\end{array}$ \\
\hline Medium & $\begin{array}{c}41 \%- \\
60 \%\end{array}$ & $\begin{array}{c}\text { The methodology is moderately effective, the evaluation results are } \\
\text { not reliable, although integrates some basic elements to make a } \\
\text { correct evaluation, the impact presents few possibilities to behave } \\
\text { according to the final result of EIS. }\end{array}$ \\
\hline Low & $\begin{array}{c}21 \%- \\
40 \%\end{array}$ & $\begin{array}{c}\text { The methodology is not effective, the evaluation results are not } \\
\text { reliable and it does not integrate the basic elements to make a } \\
\text { correct evaluation. The impact presents few possibilities to behave } \\
\text { according to the final result of EIS. }\end{array}$ \\
\hline Very low & $\begin{array}{c}0 \%- \\
\text { and }\end{array}$ & $\begin{array}{c}\text { The methodology is not effective, the evaluation results are not } \\
\text { reliable, and the impact does not have a possibility to behave } \\
\text { according to the final result of EIS. The methodology must to be } \\
\text { completely restored }\end{array}$ \\
\hline
\end{tabular}

\subsubsection{Structural Parameters Value (SPV)}

The SPV has values between 0 and 0.65 , it is compounded by four variables: i) Objectivity, ii) Totality, iii) Relevance and iv) Accuracy (Table 3). Each one is calculated from pondered indicators and values according to its particularities and conditions. The expression which integrates the four structural parameters are shown in Eq. (2).

where:

$$
\mathrm{SPV}=\gamma \mathrm{Ob}+\delta \mathrm{To}+\theta \mathrm{Re}+\phi \mathrm{Ac}
$$

$(\gamma \mathrm{Ob})=$ Objectivity; $(\delta \mathrm{To})=$ Totality $;(\theta \mathrm{Re})=$ Relevance; $(\phi \mathrm{Ac})=$ Accuracy .

2.3.2.1 Objectivity $(\gamma \mathbf{O b})$ Subjectivity can appear as a consequence of the interests of the project's proposer or as paradigms established from the core formation of each specialist. The results of the methodology regardless of its type (qualitative or quantitative) have a lack of objectivity as long as they do not establish accurate rules to evaluate impact. However, the combined use of different kinds of methods allows the performance of a global impact evaluation, 
Table 3: Indicators to evaluate the SPV.

\begin{tabular}{|c|c|c|c|c|}
\hline $\mathbf{V}$ & $\mathbf{A b}$ & Indicator & Description & Value \\
\hline \multirow{3}{*}{ 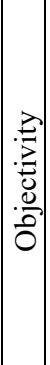 } & \multirow{3}{*}{$\sum_{Z}^{0}$} & \multirow{3}{*}{$\begin{array}{c}\text { Number of different } \\
\text { kinds of methods or } \\
\text { methodologies with } \\
\text { evaluation } \\
\text { parameters } \\
\text { established } \\
\text { previously }\end{array}$} & $\begin{array}{c}\text { Exclusive use of a quantitative or a qualitative } \\
\text { method without justified parameters to do the } \\
\text { impact evaluation }\end{array}$ & 0 \\
\hline & & & $\begin{array}{l}\text { Exclusive use of a quantitative or a qualitative } \\
\text { method with justified parameters to do the impact } \\
\text { evaluation }\end{array}$ & 0.5 \\
\hline & & & $\begin{array}{l}\text { Use of two or more methods of different kind with } \\
\text { justified parameters to do the impact evaluation }\end{array}$ & 1 \\
\hline \multirow{2}{*}{ 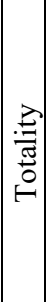 } & \multirow{2}{*}{ ষ্ট } & \multirow{2}{*}{$\begin{array}{l}\text { Components or } \\
\text { environmental } \\
\text { factors included in } \\
\text { the EIS }\end{array}$} & $\begin{array}{l}\text { Omission of one or more components or } \\
\text { environmental factors proposed by the authority, } \\
\text { according to the characteristics of the project or } \\
\text { activity location. }\end{array}$ & 0 \\
\hline & & & $\begin{array}{c}\text { Include all the components or environmental factors } \\
\text { proposed by the authority, according to the } \\
\text { characteristics of the project or activity location. }\end{array}$ & 1 \\
\hline \multirow{5}{*}{ 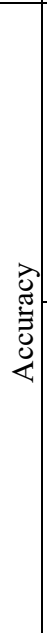 } & \multirow{2}{*}{ 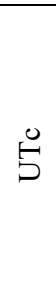 } & \multirow{2}{*}{$\begin{array}{l}\text { Use of technical- } \\
\text { scientific protocols, } \\
\text { required by the } \\
\text { environmental } \\
\text { authority or the } \\
\text { characteristics of } \\
\text { the project or } \\
\text { activity }\end{array}$} & $\begin{array}{l}\text { Protocols and techniques required by the } \\
\text { environmental authority or the characteristics of the } \\
\text { project or activity are not executed. }\end{array}$ & 0 \\
\hline & & & $\begin{array}{l}\text { Protocols and techniques required by the } \\
\text { environmental authority or the characteristics of the } \\
\text { project or activity are executed. }\end{array}$ & 1 \\
\hline & \multirow{3}{*}{$\stackrel{0}{\ominus}$} & \multirow{3}{*}{$\begin{array}{l}\text { Suitability of } \\
\text { techniques used }\end{array}$} & $\begin{array}{l}\text { The technique is not replicable and it does not part } \\
\text { of an academic study }\end{array}$ & 0 \\
\hline & & & $\begin{array}{l}\text { The technique has been academically evaluated but } \\
\text { is not supported by scientific publications. }\end{array}$ & 0.5 \\
\hline & & & $\begin{array}{l}\text { The technique has been academically evaluated and } \\
\text { is supported by a systematic research and scientific } \\
\text { publications. }\end{array}$ & 1 \\
\hline \multirow{3}{*}{ 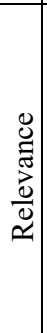 } & \multirow{3}{*}{ ¿ } & \multirow{3}{*}{\begin{tabular}{|} 
Number of \\
irrelevant attributes \\
included in the \\
impact evaluation
\end{tabular}} & $\begin{array}{c}\text { Includes three or more of the next attributes in the } \\
\text { environmental impacts evaluation: MO, EF, RB and } \\
\text { PO. }\end{array}$ & 0 \\
\hline & & & $\begin{array}{c}\text { Includes one or two of the next attributes in the } \\
\text { environmental impacts evaluation: MO, EF, RB and } \\
\text { PO. }\end{array}$ & 0.5 \\
\hline & & & $\begin{array}{l}\mathrm{MO}, \mathrm{EF}, \mathrm{RB} \text { and } \mathrm{PO} \text { attributes in the assessment of } \\
\text { environmental impacts are not included. }\end{array}$ & 1 \\
\hline
\end{tabular}


reducing the uncertainty factor in the final result. Consequently, the index objectivity value is determined considering the combined use of methods or methodologies of different natures and low dependency in the evaluator's criteria. According to results from the experts' consultation, objectivity has a superior ponderation regarding other variables compiled in the SPV, $(\gamma=0.4)$, the final value ranges between 0 and 0.4 .

2.3.2.2 Totality ( $\boldsymbol{\delta}$ To) Totality is understood as the incorporation of every environmental component and factor that may be affected by the construction work or activity from whom it is presented the EIS, according to the location site. Omission of any of these components represents an environmental impact that possibly has not been identified and therefore it has not been evaluated. Thereby, impact evaluation loses its integrality represented in the characterization of every possible alteration generated from the development of the concerned PWA. The indicator which assigns a value to this variable was made by reference to the amount of components that must be evaluated according to the guidelines provided by competent authorities (physical media, biotic and sociocultural). This indicator does not have an average value since once the effectiveness component is omitted, effectiveness on the evaluation decreases. It has a ponderation of $\delta=0.1$, thus its results ranges from 0 and 0.1 .

2.3.2.3 Accuracy $(\phi A c) \quad$ Accuracy evaluated the use of suitable, standardized and replicable techniques adjusted to the purpose of the analysis. The methodology for the submission of environmental studies proposes several techniques and protocols intended for such purpose. However, even though freedom to characterize some components according to the entrusted professional is given, this can produce uncertainty in the evaluation results if it is not chosen the right technique for the purpose of the analysis. To conduct this selection, it must be taken into account that technique becomes an investigation item supported by an academy or a specialized institution, thus, being replicable. There were defined indicators to calculate this variable considering the use of the techniques suggested by an environmental authority and the inclusion of other techniques, as long as they are supported by registrations previously mentioned. Accuracy value is calculated from the multiplication of the qualification if this indicators, (Eq. (3)). Establishing that $\phi=0.3$, is stated that the value of totality ranges between 0 and 0.3 .

where:

$$
\phi A C=U T c x \text { ITc }
$$

$\phi R g=$ accuracy; UTc $=$ qualification of the indicator "use of technical-scientific protocols, required by the environmental authority or the characteristics of the project or activity"; ITc = qualification of the indicator "suitability of techniques used".

2.3.2.4 Relevance $(\boldsymbol{\theta R e})$ Pertinence symbolizes inclusion of accurate attributes for impact evaluation. In Colombia it prevails the use of quantitative evaluation methodologies, in which impact is qualifies from included attributes in 
the evaluator's criteria, which represent a subjective and inaccurate exercise. Martinez [14] mentions that some of the uncertainty sources associated with qualification impact attributes are: i) inclusion of non-contributing attributes to the assessment of impact relevance and ii) inclusion of attributes according to importance that are subsequently unevaluated. Toro [15] present an adjustment proposal in qualitative methodology eliminating three attributes from the equation proposed by Conesa [16]: i) moment (MO), ii) effect (EF) and iii) retrievability (RB). At the same time, Martinez [17] recommends the exclusion of probability of occurrence (PO), since its estimation is nearly impossible keeping in mind the stochasticity of the environment and it can only be considered if involves historic series of the frequency of the event's occurrence. Thus, the proposed indicator determines that a high value in accuracy with the environmental evaluation must be linked with the exclusion of said attributes to evaluate impact. This variable has a ponderation of $\phi=0.2$, therefore its values variate between 0 and 0.2 .

\subsubsection{Uncertainty Factor (UF)}

Evaluation of environmental impacts is an exercise performed from predictions, since it makes a comparison between what would happen if the project gets executed and what would happen if it does not. Even though evaluators have the needed tools to determine the significance of al impact, they cannot predict with precision due to the dynamic condition of the environment. This relates with random or exogenous uncertainty mentioned by the Institute of Medicine [18], which occurs when there are natural variations in an ecosystem than cannot be controlled nor reduce when collecting data. From the experts' consultation a UF is proposed with a value of 0.05 which represents uncertainty generated by the changing condition of the evaluated location and the impossibility of estimating accurately the impact, meaning that an impact evaluation methodology cannot be completely effective.

\subsubsection{Operative Parameters Value (OPV)}

The OPV analyzes require resources to execute a methodology and the optimization of that resources in the course of the process, hence it might be considered as an element which represents efficiency in methodology. It includes three analysis parameters: i) interdisciplinarity, ii) expertise and iii) participation (Table 4). The mathematical expression related to these concepts is depicted in Eq. (4).

where

$$
\mathrm{OPV}=\gamma \mathrm{Ex}+\rho \mathrm{It}+\sigma \mathrm{Pa}
$$

$\rho \mathrm{It}=$ interdisciplinarity $; \mathrm{Ex}=$ expertise $; \mathrm{Pa}=$ participation.

2.3.4.1 Interdisciplinarity ( $\mathrm{It})$ According to Tamayo [19], interdisciplinarity is understood as the integration of results from several disciplines with different conceptual schemes of analysis, which are submitted to comparison and trial stages to be finally merged. The significance in the conformation of a group with this features and that is also under coordination supervision, is represented in the integration of efforts for the sake of a common 
objective, being in this case, the accurate evaluation of environmental impact [20]. Interdisciplinarity was included in methodology being aware of the relation between the number of professionals who constitute the evaluating team and the specialties to cover in the evaluation. Therefore, it is established that an optimal interdisciplinary group, ideal for environmental impact evaluation must have at least six professionals and every one of them must represent a study field from which the environmental evaluation is performed. Although the evaluating team may count with professionals holding several degrees and other studies which enable it to take chart of analysis in different environmental components, it is advisable that each specialty is supported by at least one professional. Thus, assuring that one person does not takes control on the evaluation of every component, being necessary the inclusion of points of view from several

Table 4: $\quad$ Indicators to evaluate the OPV.

\begin{tabular}{|c|c|c|c|c|}
\hline $\mathbf{V}$ & $\mathbf{A b}$ & Indicator & Description & Value \\
\hline \multirow{3}{*}{ 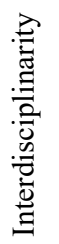 } & \multirow{3}{*}{ 䎡 } & \multirow{3}{*}{\begin{tabular}{|c|} 
Number of \\
different \\
specialists that \\
constitute the \\
evaluation group.
\end{tabular}} & Number of professionals equal or lower than 4 & 0 \\
\hline & & & 5 or 6 professionals & 0.5 \\
\hline & & & More than 6 professionals & 1 \\
\hline \multirow{5}{*}{ 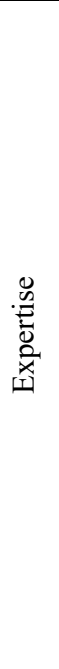 } & \multirow{2}{*}{ 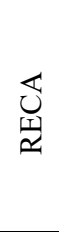 } & \multirow{2}{*}{\begin{tabular}{|} 
Relation between \\
specialties or \\
education of \\
evaluators and \\
component \\
analysis.
\end{tabular}} & $\begin{array}{l}\text { One or more specialties or training of the } \\
\text { evaluators do not match with the study } \\
\text { component. }\end{array}$ & 0 \\
\hline & & & $\begin{array}{l}\text { All specialties or training are consistent with the } \\
\text { study component }\end{array}$ & 1 \\
\hline & \multirow{3}{*}{ 㭊 } & \multirow{3}{*}{$\begin{array}{l}\text { Approximate } \\
\text { educational } \\
\text { background of } \\
\text { evaluators }\end{array}$} & $\begin{array}{l}\text { Evaluators do not have graduate degrees or } \\
\text { additional training, minimum experience of } 3 \\
\text { years related to the specialty they represent }\end{array}$ & 0 \\
\hline & & & $\begin{array}{l}50 \% \text { of the evaluators have graduate degrees or } \\
\text { additional training, minimum experience of } 3 \\
\text { years related to the specialty they represent }\end{array}$ & 0.5 \\
\hline & & & $\begin{array}{c}\text { More than } 50 \% \text { of the evaluators have graduate } \\
\text { degrees or additional training, minimum } \\
\text { experience of } 3 \text { years related to the specialty they } \\
\text { represent }\end{array}$ & 1 \\
\hline \multirow{2}{*}{ 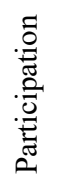 } & \multirow{2}{*}{ 战 } & \multirow{2}{*}{$\begin{array}{c}\text { Community } \\
\text { participation in the } \\
\text { impacts } \\
\text { assessment }\end{array}$} & $\begin{array}{l}\text { There is not any bound between the community } \\
\text { suggestions and the final impacts assessment. }\end{array}$ & 0 \\
\hline & & & $\begin{array}{l}\text { There is a bound between the community } \\
\text { suggestions and the final impacts assessment. }\end{array}$ & 1 \\
\hline
\end{tabular}


disciplines. This variable has a ponderation of $\rho=0.35$, therefore it is established that its result range between 0 and 0.35 .

2.3.4.2 Expertise $(\gamma \mathbf{E x})$ Expertise represents the coherence among the formation of professionals constituting the work team and the analyzing component. Each specialist must recognize the abilities that possess in order to develop a labor and inasmuch as he has been formed recognize the areas in which he can provide a specialized concept. The fact that he performs a function different from his original formation represents an uncertainty factor because the judgments that may be produced can lack reliability due to the ignorance of the correspondent specialty. For that matter, two indicators are established i) RECA, the relation between specialties or education of evaluators and component analysis, and ii) NFE, Approximate educational background of evaluators, because this can support the results of the assessment. The value of expertise is calculated from multiplying the qualification of these indicators (Eq. (5)).

$$
\gamma \mathrm{Ex}=\mathrm{RECA} \times \mathrm{NFE}
$$

where:

$\gamma \mathbf{E x}=$ Expertise; RECA $=$ qualification of the indicator "relation between specialties or education of evaluators and component analysis"; NFE = qualification of the indicator "approximate educational background of evaluators". This variable has a ponderation superior to others compiled in the OPV $(\gamma=0.4)$, hence the final value is in a range of 0 and 0.4 .

2.3.4.3 Participation ( $\sigma \mathbf{P a}$ ) Participation represents the inclusion of interested parties in impact evaluation. The Function of participation in the EIA is to legitimize the process and control public opinion regarding the project, avoiding mistrust and new disputes amongst the parts [21], allowing consensus and prevention conflict [22]. Sánchez [23] recognized that one of the strengths of the citizens' participation process in Colombia is exteriorization in the unconscious collective of its right to participate. However, it focuses on approvals more than collective construction even in cases when a previous consultation is required, participation does not get to be proactive, since an already made environmental impact assessment is presented to the public. For the purpose of highlighting the importance of proactive participation, an indicator is presented which takes into account inclusion of the concept given by community about the significance of impacts that may manifest when executing construction work or an activity developed in their influence location.

\subsection{Index application}

During a 2012-2014 period 285 environmental licenses were issued, which require an EIS presentation. The projects associated with importation and transportation of chemical substances used as agricultural chemicals, pesticides, or those employed in veterinarian use, were excluded from the assessment since they represent risk analysis that do not use impact evaluation methodologies, therefore a sample of 168 EIS is established. Once its verified that the authority 
provide thorough information from every study, it is determined that only 131 studies achieve this profile, which represent $46 \%$ of the ones presented during the previously mentioned period.

Objectivity in impacts evaluation decreases due to the lack of parameters to perform the exercise. Only $2.29 \%$ of the methodologies combine different kinds of methods and indicators to validate the final qualification of the impact. $6.11 \%$ of the methodologies justify the final concept through indicators, although they do not combine the use of methods from different nature. Accuracy is evidenced in the use of techniques and protocols required by authorities. Since only $0.76 \%$ methodologies use unknown techniques with low academic support. Overall, every component or environmental factors are included in the environmental assessment. However, most of the methodologies employs low pertinence attributes in order to evaluate impacts, significantly affecting objectivity in the methodology (Table 5).

Table 5: Results of the SPV parameters.

\begin{tabular}{cccccccc}
\hline $\mathrm{Ob}$ & \% of Meth & Ac & \% of Meth & Re & \% of Meth & To & \% of Meth. \\
\hline 0 & 91.60 & 0 & 0.76 & 0 & 58.02 & 0 & 1.53 \\
0.5 & 6.11 & 0.5 & 0 & 0.5 & 32.82 & 1 & 98.47 \\
1 & 2.29 & 1 & 99.24 & 1 & 9.16 & & \\
\hline
\end{tabular}

It is evidenced that the implementation of the methodologies is accurate since $96.1 \%$ of the teams conducting the EIS satisfy the conditions required to perform an interdisciplinary evaluation, nonetheless only $4.58 \%$ of the methodologies integrate the opinion of the community in impacts evaluation (Table 6).

Table 6: Results of the OPV parameters.

\begin{tabular}{cccccc}
\hline It & \% of Meth & Ex & \% of Meth & Pa & \% of Meth \\
\hline 0 & 0.76 & 0 & 2.29 & 0 & 95.42 \\
0,5 & 3.05 & 0.5 & 67.18 & 1 & 4.58 \\
1 & 96.18 & 1 & 30.53 & & \\
\hline
\end{tabular}

From index application it is established that none of the presented studies were using effective methodologies, $66.4 \%$ present methodologies with an average effectiveness, $29.7 \%$ low effectiveness methodologies and $1.5 \%$ of the sample use methodologies that require a complete reassessment since they do not obtain a positive qualification for any of the analysis parameters (Table 7).

Table 7: $\quad$ Final results of the EM.

\begin{tabular}{ccc}
\hline EIM & N Methodology & $\%$ of Meth \\
\hline $81 \%-95 \%$ & 1 & $0.76 \%$ \\
$61 \%-80 \%$ & 3 & $2.29 \%$ \\
$41 \%-60 \%$ & 87 & $66.41 \%$ \\
$21 \%-40 \%$ & 39 & $29.77 \%$ \\
$0 \%-20 \%$ & 1 & $0.76 \%$ \\
\hline
\end{tabular}


This indicates that the decisions made by an environmental authority have EIS as basis, with results whose lack of certainty represent possible impacts related with the project to execute. Thus proposed actions for environmental management will be insufficient producing irreversible damages not taking into consideration misevaluated impacts. A consequence of EIS ineffectiveness cannot be evidenced in short term; in fact, it cannot be associated with the normative control since authorities are flexible in several parameters regarding the submission of these studies. Therefore, implementation of the index as a control and tracking instrument for EIS is advised, performed by proponents and the authority compiling as a common objective a transparent and effective evaluation.

\section{References}

[1] Ortolano, L., Jenkins, B., \& Abracosa, R. P. Speculations on when and why EIA is effective. Environmental Impact Assessment Review, 7(4), pp. 285292, 1987.

[2] Leu, W. S., Williams, W. P., \& Bark, A. W. Development of an environmental impact assessment evaluation model and its application: Taiwan case study. Environmental Impact Assessment Review, 16(2), pp. 115-133, 1996.

[3] Sadler, B. (ed). International Study of the Effectiveness of Environmental Assessment Final report environmental assessment in a changing world: Evaluating Practice to Improve Performance. Environmental Agency, International Association for Impact Assessment, Minister of Supply and Services Canada, 1996.

[4] Wood, C. M. Environmental Impact Assessment: A Comparative Review. London: Prentice Hall, 2003.

[5] Sadler, B., \& McCabe, M. Environmental impact assessment training resource manual (Vol. 1). UNEP Division of Technology, Industry and Economics and Trade Branch, 2002.

[6] Tennøy, A., Kværner, J., \& Gjerstad, K. I. Uncertainty in environmental impact assessment predictions: The need for better communication and more transparency. Impact Assessment and Project Appraisal, 24(1), pp. 45-56, 2006.

[7] Flyvbjerg, Bent, Nils Bruzelius and Werner Rothengatter. Megaprojects and risk. An anatomy of ambition. Cambridge: Cambridge University Press, 2003.

[8] Wood, C., Dipper, B., \& Jones, C. Auditing the assessment of the environmental impacts of planning projects. Journal of Environmental Planning and Management, 43(1), pp. 23-47, 2000.

[9] Buckley, R How accurate are environmental impact predictions? Ambio, 20(3-4), 1992.

[10] Senécal, P., Goldsmith, B., Conover, S., Sadler, B., \& Brown, K. Principles of environmental impact assessment best practice. Special Publication, International Association for Impact Assessment, Fargo, USA, 1999. 
[11] Munn, R. E. "Environmental impact assessment: principles and procedures: SCOPE workshop on impact studies in the environment, WISE." Report/Scientific committee on problems of the environment $\mathrm{N}^{\circ} 5,1975$.

[12] De Camino, G. R., \& Muller, S. Esquema para la definición de indicadores. Sostenibilidad de la agricultura y los recursos naturales, 38, pp. 164-213, 1993.

[13] García Valdés, M., \& Suárez Marín, M. El método Delphi para la consulta a expertos en la investigación científica. Revista Cubana de Salud Pública, 39(2), pp. 253-267, 2013.

[14] Martínez, L. Análisis de la Incertidumbre en los Estudios de Impacto Ambiental en Colombia desde el Enfoque de los Sistemas Complejos. Master's Thesis. Universidad Nacional de Colombia. Bogotá, 2012.

[15] Toro, J., Requena, I., \& Zamorano, M. Environmental impact assessment in Colombia: Critical analysis and proposals for improvement. Environmental Impact Assessment Review, 30(4), pp. 247-261, 2010.

[16] Conesa, V. Guía metodológica para la evaluación del Impacto Ambiental. pp. 412. Madrid: Mundi-Prensa Libros, 1995.

[17] Martínez, R. Propuesta metodológica para la evaluación de impacto ambiental en Colombia. Master's Thesis. Universidad Nacional de Colombia. Bogotá, 2010.

[18] Institute of Medicine. Environmental decisions in the face of uncertainty. Washington, DC: The National Academies Press, 2013.

[19] Tamayo, M. La investigación. Serie Aprender a investigar. Instituto Colombiano para el fomento de la educación superior. Bogotá, 1999.

[20] Reinoso, L. Criterios para la elaboración de estudios de impacto ambiental. Secretaría de Ambiente y Desarrollo Sustentable de la Nación, Buenos Aires: 2014.

[21] Tripp, J; Alley, N. Streamlining NEPA's environmental review process: suggestion for agency reform. NY Univ Environ Law J 2003;12: pp. 75110, 2003.

[22] Wilkins, H. The need for subjectivity in EIA: discourse as a tool for sustainable development. Environmental Impact Assessment Review; 4: pp. 401-14, 2003.

[23] Sánchez, M. Análisis de la participación ciudadana en los procesos de Evaluación de Impacto Ambiental. Master's Thesis. Universidad Nacional de Colombia. Bogotá, 2012. 